\title{
Spacecraft Interaction Test Results of the High Performance Hall System SPT-140
}

J. M. Fife and W. A. Hargus, Jr.

U. S. Air Force Research Laboratory

Edwards AFB, CA

D. A. Jaworske. C. Sarmiento. L. Mason, and R. Jankovsky

NASA Glenn Research Center

Cleveland, $\mathrm{OH}$

J. S. Snyder and S. Malone

Space Systems/Loral

Palo Alto. CA

J. Haas and A. Gallimore

University of Michigan

Ann Arbor, MI

\begin{abstract}
Crombl tests were performed to help characterize modes of interaction between the SPT-140 Hall thruster and wacciaft components. The experiments were performed at NASA Glenn Research Center and at the University of Michigen. Measurenents were made of thruster plume current density, electromagnetic interference (EMI), and stufuce sputtering and contamination. Diagnostics included Faraday probes. collimated sputter/deposition targets, and radio-frequency detectors. Ion current density measurements shosved exponential decay with off-axis angle up to approximately 30 degrees. At off-axis angles greater than 30 degrees, results varied with chamber background pressure. presumably due to ambient charge exchange plasma. Sputer rates of solar cell coverglass, Kapton, and RTV we'cucurately measured $1 \mathrm{~m}$ from the thruster exit for off-axis angles less than 60 degrees. At off-axis angles greater than 60 degrees, the sputter rate was on the order of the measurement uncertainty. EMI tests found very little emission in the raditional RF communication bands. At the lowest frequencies. one band of E-field emission ( $10 \mathrm{kHz}$ to 20 MH-I was eletected which exceeded the MIL-STD-46IC specification by up to $53 \mathrm{~dB}$.
\end{abstract}

\section{Introduction}

Owing to their high etficiency, optimal specific impulse. and relative simplicity. Hall thrusters have heen used extensively on Russian spacecraft. As electric propulsion is becoming a more acceptable sprion on U.S. spacecraft. Hall thrusters are being considered for orbit topping. stationkeeping. and repositioning missions.

Most existing flight unit Hall thrusters operate at powers between 500 and 1600 Watts. Hall thrusters wikh higher powers, on the other hand, can be used more effectively for the dual mission of orbit topping and stationkeeping of geosynchronous spacecraft. For constant orbit-topping trip time. higher power Hall thrusters can yield significant gains in payload fraction to geosynchronous orbit. ${ }^{1}$

The High Performance Hall System (HPHS) is a complete $4.5-\mathrm{kW}$ Hall-effect spacecraft propulsion svstem being developed under a cost-shared agreement between the U.S. Air Force and Atlantic Research Corporation. The goal of the HPHS program is to develop and demonstrate a Hall propulsion system capable of meeting the Integrated High Payoff Rocket Propulsion Technology (IHPRPT) Phase I Goals. The target performance of the system is:

\begin{tabular}{|l|l|}
\hline Thruster Specific Impulse & 1800 seconds \\
\hline Overall System Efficiency & $51 \%$ \\
\hline Specific Mass (Thruster. PPU) & $6.0 \mathrm{~kg} / \mathrm{kW}$ \\
\hline Life & 7200 hours \\
\hline
\end{tabular}

A key element of HPHS is the SPT-140 Hall thruster. which is being developed by Engineering Design Bureau (EDB) Fakel in Kaliningrad, Russia. Under the HPHS program, a series of risk reduction tests was conducted in the U.S. using the SPT-140 Demonstration Model 3 (DM3). The DM3 had accumulated 8 hours during acceptance testing in Russia. It was then shipped to the U.S. where it underwent the testing reported in this paper. which involved 155 hours of additional firing.

Three categories of testing were performed to help quantify the integration effects of an SPT-140 Hall thruster with spacecraft. The first test series. performed at NASA Glenn Research Center (GRC) 


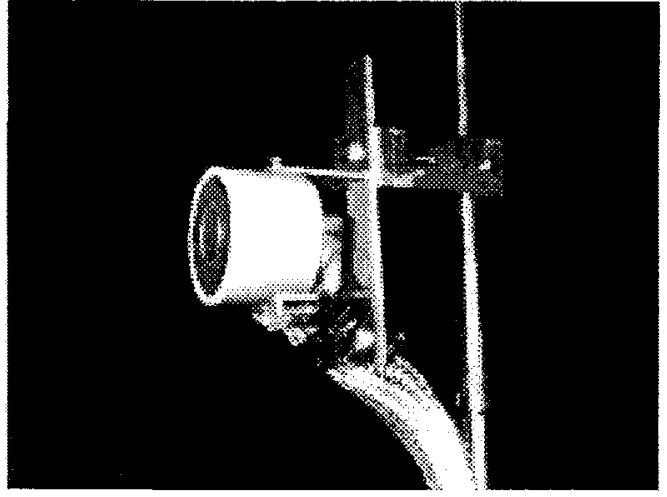

Fig. 1. Photograph of AFRL Faraday probe.

from $8 / 6 / 99$ to $9 / 7 / 99$, included performance, sputtering and contamination, and electromagnetic interference (EMI) tests. The second test series, performed at the University of Michigan Plismadvnamics and Electric Propulsion Laboratory (PEPL) from $9 / 20 / 99$ to $9 / 28 / 99$, included plume characterization tests. Condensed results from the plume characterization. sputtering and contamination. and EMI tests are presented in this paper. The results of the performance tests will be presented in a separate paper.

\section{Facility Descriptions}

Tests at NASA GRC were performed in Vacuum Fixility $\# 6$ (VF-6). VF-6 is a $21-\mathrm{m}$ long by $8-\mathrm{m}$ diameter. horizontal vacuum chamber located in the Electric Propulsion Laboratory at GRC. The chamber is cryogenically pumped at a speed of 300,000 hiters/sec on xenon. Grafoil ${ }^{\text {s. }}$ sputter suppression material lines the interior wall. Pressure measurements were made near the midpoint of the chamber's side wall using a screen-mesh-shielded iunization pressure gauge calibrated on air.

Tests at PEPL were performed in the 9 -m long by $6-\mathrm{m}$ diameter stainless-steel clad Large Vacuum Test Ficility (LVTF). The LVTF uses four LN2-cooled CVI TM 1200 reentrant cryopumps. giving a measured xenon pumping speed of $140.000 \mathrm{l} / \mathrm{s}$. The chamber hils at louvered $1.8-\mathrm{m}$ by 1.8 -m graphite beam dump in the center of the end cap. downstream of the thruster plume. Pressure measurements were made near the midpoint of the chamber's side wall using an ionization pressure gauge calibrated on air.

\section{Plume Characterization}

The plume test series described here was designed to be a L.S. risk reduction experiment. A more extensive undy was performed at Fakel by Kozubsky, et al. ${ }^{3}$

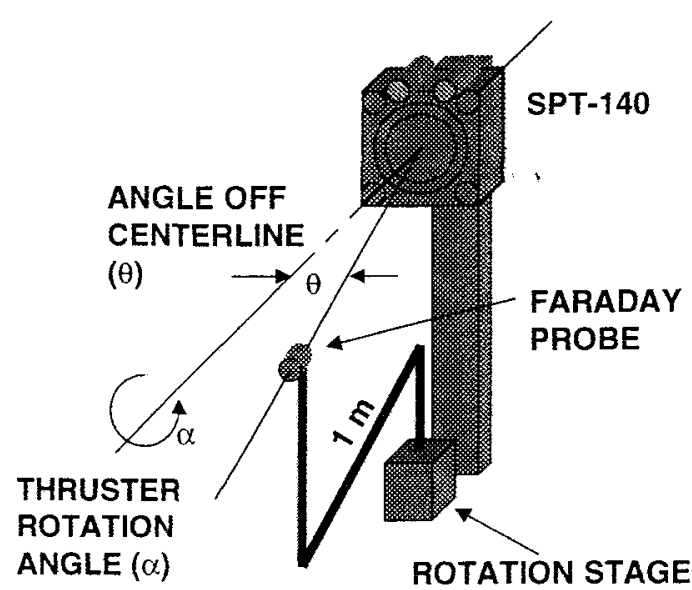

Fig. 2. Illustration of the orientations of the Faraday probe and thruster.

The measurements described here, performed at PEPL, consist primarily of ion current density. In addition. an attempt was made to measure far-field ion energy spectra. However, difficulty with spectrometer calibration precluded obtainment of accurate quantitative results. ${ }^{+}$Therefore, this paper will focus on the ion current density measurements.

\section{Test Setup}

Inside the LVTF at PEPL. the thruster was mounted on a stepper-motor-driven mechanism which could rotate the thruster about its centerline. The centerline of the thruster was in the horizontal plane. with the thruster exit toward the graphite beam dump on the back wall of the chamber.

The diagnostic setup was similar to those performed before at NASA GRC. 5.6

The Faraday probe, provided by the Air Force Research Laboratory (AFRL), consisted of a molybdenum collector 0.75 inches in diameter surrounded by a molybdenum guard ring with an inner diameter of 0.85 inches and an outer diameter of 1.70 inches. A ring of Macor machinable ceramic electrically insulated the collector and guard ring. Fig. 1 is a photograph of the probe showing the center collector, guard ring, and outer Macor insulator. As Fig. 2 shows. the Faraday probe was oriented facing the center of the thruster exit plane. $1 \mathrm{~m}$ away. The probe was mounted on a vertical post, which was in turn mounted to a horizontal boom whose center of rotation was aligned with the exit plane of the thruster. This allowed the probe to be swept through a horizontal plane extending through the center of the thruster. at a constant radius. \pm 100 degrees off centerline. The uncertainty in the probe angle was \pm 2 degrees. 
The Faraday probe collector and guard ring were each biased to - $15 \mathrm{~V}$ using separate power supplies. A 40S2 shunt was placed between the collector and its power supply. The voltage across the shunt was measured on an AM 501 operational amplifier antached to a Tektronix TDS 540 oscilloscope.

\section{Test Procedure}

The SPT-140 was operated at constant $300 \mathrm{~V}$ discharge. By varying the propellant flow rate, three power settings were tested: 2,3 , and $4.5 \mathrm{~kW}$. At each power setting. measurements were taken at 6 orientations of the thruster rotated about its centerline: $\alpha=-60,-30,0,30,60$, and 90 degrees. Rotation is positive counterclockwise looking at the thruster face, and. at zero degrees, the cathodes are on top of the thruster. At each power setting and thruster rotational orientation. Faraday probe sweeps were performed for $-100<\theta<100$ degrees off thruster centerline, at 1 . desree increments.

\section{Results and Discussion}

The chamber pressures were $8.3 \times 10^{-6}, 1.2 \times 10^{-5}$ and $1.6 \times 10^{5}$ Torr (xenon) at 2.3 , and $4.5 \mathrm{~kW}$ powers, respectively

Fig. 3 shows the ion current densities measured $1.0 \mathrm{~m}$ from the thruster exit. For off-axis angles less than approximately 30 degrees, decay of ion current density is exponential with $\theta$. The instrumentation measurement uncertainty was estimated to be $3 \%$ for the majority of the ion current density values, dominated by calibration processes. However, in the tiils of Fig. 3. for ion current densities less than about 0.2 $\mathrm{mA} / \mathrm{cm}^{2}$, discretization error begins to dominate. increasing the measurement uncertainty to ipproximately $7 \mu \mathrm{A}_{\mathrm{cm}^{2}}$, or $6 \%$, in those regions. It should be noted that these values strictly represent the uncertainty introduced by the measurement devices. As will he explained below. the uncertainty in the estimate of emitted ion beam current may be much higher due to ambient charge exchange plasma.

For all of the cases, very little (less than 1 degree) mational asymmetry is seen. However. a common heam offset of approximately 2 degrees is apparent. This appears regardless of rotation. indicating that this offset is due to angular position error of the Faraday probe swing-arm. which was aligned to \pm 2 degrees.

An estimate of the total ion beam current can be ohtained by integration of the curves in Fig. 3 as.

$$
I_{B}=2 \pi r^{2} \int_{0}^{\pi / 2} j(\theta) \sin (\theta) d \theta .
$$

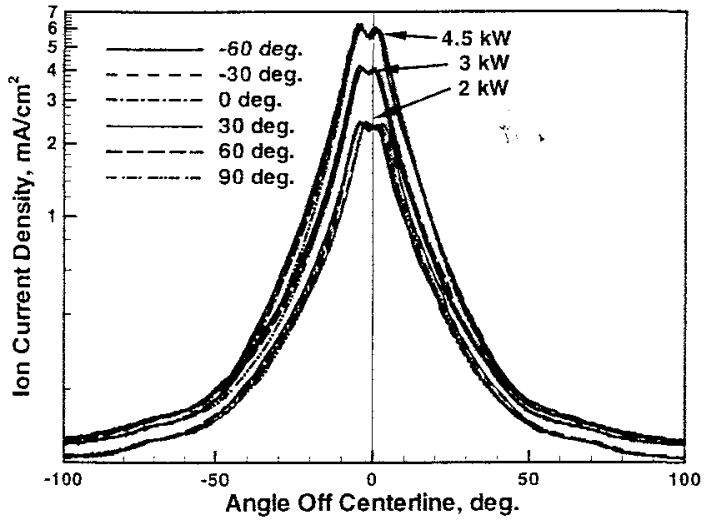

Fig. 3. Measured ion current density $1 \mathrm{~m}$ from thruster exit at 2,3 , and $4.5 \mathrm{~kW}$ discharge power.

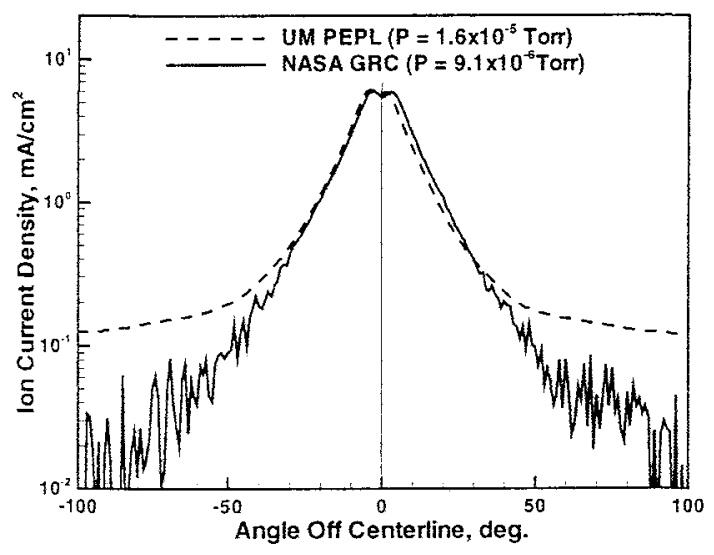

Fig. 4. Comparison of NASA GRC and UM PEPL ion current density measurements $1 \mathrm{~m}$ from thruster exit at $4.5 \mathrm{~kW}$ discharge power. $\alpha=0 \mathrm{deg}$.

where $r$ is the radial distance from the thruster exit to the Faraday probe, $j$ is the measured ion current density, and $\theta$ is the angle off-centerline. For 2, 3, and $4.5 \mathrm{~kW}, I_{B}$ is found (using the trapezoidal rule) to be 13.2. 17.1, and 21.8 Amperes, respectively. These values are approximately twice the expected beam currents. which are 5.0, 7.8, and 11.4 Amperes, calculated by estimating a propellant utilization of $94 \%{ }^{7}$ a double-ion fraction of $0.04 .^{7}$ and a cathode flow fraction of $5 \%$. This discrepancy has been studied before. ${ }^{8}$ and is believed to be due to additional collection of ambient low-energy charge exchange ions that we will call $j_{a}$. To first order, assuming $j_{a}$ is constant versus $\theta . \mathrm{j}_{\mathrm{a}}$ must be $0.131,0.148$, and 0.166 $\mathrm{mA} / \mathrm{cm}^{2}$ for 2.3 , and $4.5 \mathrm{~kW}$, respectively. This is a significant fraction of the ion current density in the extremities of the beam for $\mid \theta \triangleright 40^{\circ}$. but is small compared to the measured values near centerline.

Current-density data at $4.5 \mathrm{~kW}$ and $\alpha=0$ degrees were also acquired as a part of the performance testing at GRC, where the chamber pressure at this power level 


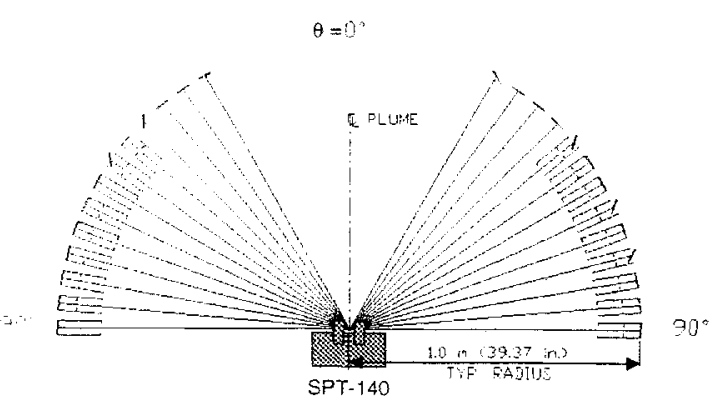

Fig. 5. Illustration of the placement of exposure samples with respect to the SPT-140.

was nearly a factor of two lower than at PEPL. The Faraday probe used in the GRC tests had the same collector dimensions, collector material, and electrical bias as the AFRL probe. Fig. 4 shows data from both facilities at the same thruster operating condition. Note that neither data set has been corrected for probe offset trom the thruster centerline, thus they appear to he shifted from each other. In the plume core, the data are very similar. Farther from the thruster centerline. where charge-exchange plasma would be expected to cominate. the GRC data are much lower though noisier) than the PEPL data. This comparison supports the hypothesis that the additional current collected was lue to ambient charge-exchange ions, which would be expected to decrease with decreasing chamber hackground pressure. Integration of the GRC Faraday probe data yields $I_{R}=16.6 \mathrm{~A}$. much smaller than the PEPL data. yet still larger than the expected beam current.

\section{Sputtering and Contamination}

The sputtering and contamination test was performed in VFG at NASA GRC. The test involved placement if sputtering targets $1 \mathrm{~m}$ from the thruster exit at arious off-axis angles and at various angles of incidence. Thruster firing duration was 100 hours at 3 kW

\section{Test Setup}

The sputtering and contamination test setup was similar to one used previously by E. Pencil et al. at GRC." It consisted of various 4- $\mathrm{cm}^{2}$ samples, most of which were enclosed in collimators, affixed to a $1-\mathrm{m}$ radius semicircle as shown in Fig. 5. The semicircle placed the collimators in the horizontal plane bisecting the thruster plume. The actual samples. after mounting, were $1.0 \mathrm{~m} \pm 1 \mathrm{~cm}$ from the thruster exit. The stainless steel semicircle frame was covered with Grafoil sputter suppression material.

The samples were secured to a metallic holder and masked by tantalum foil so that approximately $2 \mathrm{~cm}^{2}$ of area was exposed. Most of the sample holders were placed in collimators that had two circular molybdenum apertures located 5.72 and $15.24 \mathrm{~cm}$ in front of the sample. The aperture diameters were 2.69 and $3.83 \mathrm{~cm}$ in diameter, respectively. The collimator axes were aligned radially toward the center of the thruster exit plane.

Four sample types were tested: solar cell cover glass. RTV silicone. Kapton $\AA^{\circledR}$, and optical solar reflector (OSR). Table 1 shows where each sample was placed. its angle of incidence to the beam, and whether or not it was placed in a collimator.

Collimators were aligned on the semicircle and tested

Table 1. Sample type, off-axis angle $(\theta)$, angle of incidence $(\phi)$ to the ion beam, and mount type.

\begin{tabular}{|c|c|c|c|}
\hline$\theta(\mathbf{d e g})$ & $\phi(\mathbf{d e g})$ & Sample Type & $\begin{array}{c}\text { Collimator } \\
(\mathbf{Y} / \mathbf{N})\end{array}$ \\
\hline-90 & 0 & Cover Glass & $\mathrm{Y}$ \\
\hline-85 & 0 & Cover Glass & $\mathrm{Y}$ \\
\hline-80 & 0 & Cover Glass & $\mathrm{Y}$ \\
\hline-75 & 0 & Cover Glass & $\mathrm{Y}$ \\
\hline-70 & 0 & Cover Glass & $\mathrm{Y}$ \\
\hline-65 & 0 & Cover Glass & $\mathrm{Y}$ \\
\hline-60 & 0 & Cover Glass & $\mathrm{Y}$ \\
\hline-55 & 45 & OSR & $\mathrm{Y}$ \\
\hline-50 & 0 & Cover Glass & $\mathrm{Y}$ \\
\hline-45 & 45 & RTV & $\mathrm{N}$ \\
\hline 40 & 0 & Cover Glass & $\mathrm{N}$ \\
\hline-35 & 0 & Kapton & $\mathrm{N}$ \\
\hline-30 & 0 & Cover Glass & $\mathrm{N}$ \\
\hline 30 & 30 & Cover Glass & $\mathrm{N}$ \\
\hline 35 & 0 & OSR & $\mathrm{N}$ \\
\hline 40 & 0 & RTV & $\mathrm{N}$ \\
\hline 45 & 0 & RTV & $\mathrm{N}$ \\
\hline 50 & 60 & Cover Glass & $\mathrm{Y}$ \\
\hline 55 & 0 & OSR & $\mathrm{Y}$ \\
\hline 60 & 0 & Kapton & $\mathrm{Y}$ \\
\hline 65 & 45 & Cover Glass & $\mathrm{Y}$ \\
\hline 70 & 0 & RTV & $\mathrm{Y}$ \\
\hline 75 & 45 & Cover Glass & $\mathrm{Y}$ \\
\hline 80 & 0 & OSR & $\mathrm{Y}$ \\
\hline 85 & 0 & OSR & $\mathrm{Y}$ \\
\hline 90 & 0 & OSR & $\mathrm{Y}$ \\
\hline & & & \\
\hline
\end{tabular}

Table 2. Measurement matrix for exposure samples. $B=$ Before,$A=$ After exposure

\begin{tabular}{|c|c|c|c|}
\hline Test & $\begin{array}{c}\text { Cover } \\
\text { Glass }\end{array}$ & $\begin{array}{c}\text { RTV } \\
\text { Silicone }\end{array}$ & Kapton $^{\text {(i) }}$ \\
\hline Mass & B,A & B,A & B,A \\
\hline Profilometry & A & A & A \\
\hline Transmittance & B,A & & \\
\hline
\end{tabular}


by ensuring that the beam of a pen-laser in a modified collimator fell within $2 \mathrm{~mm}$ of the semicircle center. The alignment of the finished assembly with the thruster was validated by using the collimator/laser to illuminate points on the thruster side and face. The accuracy of this alignment is estimated to be \pm 1.3 deg.

In addition to the samples placed on the semicircle assembly, one of each type of sample was used as an in-chamber control and placed in a vented aluminum box $8 \mathrm{~m}$ behind the thruster. Also, one of each type of sample was used as a laboratory control outside the vacuum chamber.

\section{Test Procedure}

Pre- and post-exposure sample evaluation was conducted according to the matrix in Table 2 . Additional measurements were made (not shown in Table 2). which are presented in a report by Jaworske. ${ }^{10}$ OSR sample evaluations were performed outside GRC, and do not appear in Table 2.

Mass measurements of the cover glass samples were made using a Mettler M 3 scale, and were assumed accurate to $\pm 0.000001 \mathrm{~g}$. based on the instrument specifications. The masses of the RTV and Kapton ${ }^{\text {at }}$ simples were out of range of the Mettler M 3, and were measured using a Sartorius RI60P scale. accurate to $\pm 0.00001 \mathrm{~g}$. Before weighing. Kapton simples were desiccated for 24 hours at 20 mTorr at ambient temperature. Cover glass and RTV were not desiccated.

Surface protilometry using a Dektek II was performed alter plume exposure to identify contaminant thickness and/or erosion loss. Minimum detectable step height using this technique was $10 \mathrm{~nm}$ based on calibration of the instrument with standard steps. The height of the step was measured at the edge of the exposed region.

Solar transmittance with respect to the air mass zero solar spectrum was obtained to \pm 0.002 before and atter plume exposure using a Perkin-Elmer Lambda19 spectrophotometer equipped with a $15 \mathrm{~cm}$ diameter integrating sphere.

Alter the samples were pre-tested according to Table 2 and mounted in holders, the unmasked area (i.e. the area exposed to the thruster plume) was estimated by photographic comparison to a calibration image. The uncertainty introduced by this method was estimated to be l\%

After photographic area estimation, exposure samples and in-chamber controls were installed in VF6. Thruster operation began after overnight pumping, and lasted for 100 hours. After cool-down and re-
Table 3. Mass loss, erosion depth, and change in total transmittance $(\Delta T T)$ for normal-incidence cover glass exposure samples after 100 hours.

\begin{tabular}{|c|c|c|c|}
\hline$\theta(\mathbf{d e g})$ & $\begin{array}{c}\text { Mass Loss } \\
\left(\mathbf{g} / \mathbf{c m}^{2}\right)\end{array}$ & $\begin{array}{c}\text { Erosion } \\
(\mathbf{n m})\end{array}$ & $\Delta \mathbf{T T}$ \\
\hline-90 & $-2.82 \times 10^{-7}$ & 30 & 0.006 \\
$\pm 1.4 \times 10^{-5}$ & \pm 13 & \pm 0.002 \\
\hline-85 & $3.30 \times 10^{-5}$ & 43 & 0.002 \\
& $\pm 1.4 \times 10^{-4}$ & \pm 16 & \pm 0.002 \\
\hline-80 & $-5.43 \times 10^{-6}$ & 36 & -0.003 \\
& $\pm 1.4 \times 10^{-5}$ & \pm 15 & \pm 0.002 \\
\hline-75 & $3.44 \times 10^{-5}$ & 190 & -0.036 \\
& $\pm 1.4 \times 10^{-5}$ & \pm 58 & \pm 0.002 \\
\hline-70 & $4.83 \times 10^{-5}$ & 140 & -0.045 \\
& $\pm 1.4 \times 10^{-5}$ & \pm 43 & \pm 0.002 \\
\hline-65 & $3.74 \times 10^{-5}$ & 210 & -0.057 \\
& $\pm 2.7 \times 10^{-5}$ & \pm 64 & \pm 0.002 \\
\hline-60 & $1.48 \times 10^{-4}$ & 380 & -0.0041 \\
& $\pm 1.7 \times 10^{-5}$ & \pm 110 & \pm 0.002 \\
\hline-50 & $9.46 \times 10^{-4}$ & 3850 & -0.012 \\
& $\pm 1.9 \times 10^{-5}$ & \pm 1200 & \pm 0.002 \\
\hline-40 & $2.93 \times 10^{-3}$ & 12000 & -0.012 \\
& $\pm 3.2 \times 10^{-5}$ & \pm 3600 & \pm 0.002 \\
\hline-30 & $6.81 \times 10^{-3}$ & 24200 & -0.006 \\
& $\pm 7.8 \times 10^{-5}$ & \pm 7300 & \pm 0.002 \\
\hline
\end{tabular}

Table 4. Mass loss and erosion depth for additional samples after 100 hours.

\begin{tabular}{|c|c|c|c|}
\hline$\theta(\operatorname{deg})$ & $\phi($ deg $)$ & $\begin{array}{c}\text { Mass Loss } \\
\left(\mathrm{g} / \mathrm{cm}^{2}\right)\end{array}$ & $\begin{array}{c}\text { Erosion } \\
\text { (nm) }\end{array}$ \\
\hline \multicolumn{4}{|c|}{ Cover Glass } \\
\hline 30 & 30 & $\begin{array}{l}9.14 \times 10^{-3} \\
\pm 9.2 \times 10^{-5}\end{array}$ & $\begin{array}{c}37900 \\
\pm 11000\end{array}$ \\
\hline 50 & 60 & $\begin{array}{r}1.14 \times 10^{-3} \\
\pm 1.8 \times 10^{-5}\end{array}$ & $\begin{array}{c}4960 \\
\pm 1500\end{array}$ \\
\hline 65 & 45 & $\begin{array}{r}3.42 \times 10^{-4} \\
\pm 5.3 \times 10^{-5}\end{array}$ & $\begin{array}{r}1060 \\
\pm 320 \\
\end{array}$ \\
\hline 75 & 45 & $\begin{array}{r}1.13 \times 10^{-3} \\
\pm 1.4 \times 10^{-5}\end{array}$ & $\begin{array}{c}350 \\
\pm 100\end{array}$ \\
\hline \multicolumn{4}{|c|}{ RTV Silicone } \\
\hline-45 & 45 & $\begin{array}{l}2.50 \times 10^{-3} \\
\pm 9.1 \times 10^{-5}\end{array}$ & $\begin{array}{l}21500 \\
\pm 6500\end{array}$ \\
\hline 40 & 0 & $\begin{array}{l}6.22 \times 10^{-3} \\
\pm 1.1 \times 10^{-4}\end{array}$ & $\begin{array}{r}18900 \\
\pm 5700\end{array}$ \\
\hline 45 & 0 & $\begin{array}{l}2.45 \times 10^{-3} \\
\pm 9.0 \times 10^{-5}\end{array}$ & $\begin{array}{r}14100 \\
\pm 4200 \\
\end{array}$ \\
\hline 70 & 0 & $\begin{array}{l}2.48 \times 10^{-4} \\
\pm 8.7 \times 10^{-5}\end{array}$ & - \\
\hline \multicolumn{4}{|c|}{ Kapton } \\
\hline-35 & 0 & $\begin{array}{l}1.90 \times 10^{-3} \\
\pm 1.4 \times 10^{-4}\end{array}$ & $\begin{array}{r}18600 \\
\pm 5600 \\
\end{array}$ \\
\hline 60 & 0 & $\begin{array}{l}2.77 \times 10^{-4} \\
\pm 1.4 \times 10^{-4} \\
\end{array}$ & $\begin{array}{r}14000 \\
\pm 4200 \\
\end{array}$ \\
\hline
\end{tabular}


pressurization. post-testing was performed according (1) Table 2.

\section{Results and Discussion}

What follows is a short sampling of some of the results from the sputtering and contamination experiment. Additional information may be found in a report by Jaworske. ${ }^{10}$

During thruster operation. chamber background pressure was $6 \times 10^{-6}$ Torr (xenon).

Tithle 3 shows the mass loss, erosion depth, and change in total transmittance for the normal-incidence solar cell cover glass exposure samples only. (Note that two of these samples, at -40 and -30 deg., were not in collimators.) Fig. 6 shows mass loss and erosion depth plotted versus off-axis angle.

Incertainty in mass loss is dominated by three sources: outgassing. area estimation (1\%), and hreakage correction. The uncertainty values in Table 3 are the RMS-combined uncertainties of these three components. which are described below.

During post-test extraction of the samples from their hollers, it was noticed that 8 of the samples (all cover glass) were adhered to their holder by epoxy which had been used to affix the molybdenum masks. Extraction from the holder required breakage of some of the corners of these samples (atl in areas covered by the molybdenum mask). The missing mass was estimated using a photographic technique and added to the final mass. Uncertainty in this correction method wits estimated using the statistics of multiple trials to the 3 is.

The in-chamber cover glass control sample lost 0.022 mer during the 100-hour test, presumably to nutgassing. Assuming this loss to be $50 \%$ probable in a nomal distribution. uncertainty (standard deviation) is found to be $1.4 \times 10^{-5} \mathrm{~g} / \mathrm{cm}^{2}$ for all samples.

Outgassing and breakage correction dominate the uncertainty calculation for most of the samples. except for $|\theta|<50$ degrees, where the $1 \%$ area measurement uncertainty is most significant. For $|\theta|>60$ degrees. the uncertainty is of the same order as the mcisurement. Precision of similar mass loss experiments in the future may be improved by increasing the firing duration and attempting to account for outgassing as systematic error.

Erosion depth. given in Table 3 and Fig. 6, is seen to follow the same trend as mass loss. Calibration of the protilometer was based on measurement of two standard steps. For well-detined steps such as the calibration standards. the profilometer yields accurate

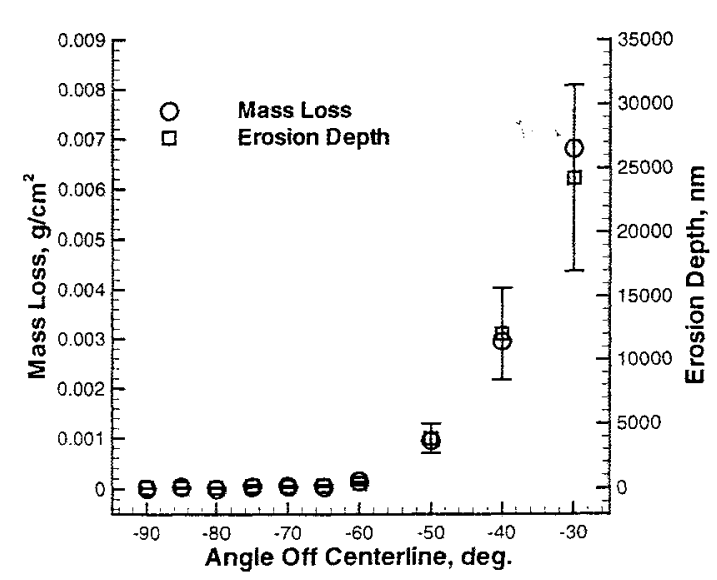

Fig. 6. Erosion depth and mass loss for 100-hour cover glass exposure samples.

step height value $\pm 10 \mathrm{~nm}$. For less well-defined steps, it was necessary to measure the topography in the vicinity of the step, and estimate an idealized step height. In these cases, the step height was estimated using an extrapolation technique which had an accuracy of $\pm 30 \%$.

As a check on mass loss and step height measurements. the sample density was estimated by dividing the mass loss per unit area by the step height. The mean result for the seven innermost samples (i.e. those where there was net erosion) was $2.66 \mathrm{~g} / \mathrm{cm}^{3}$, which is very close to the known cover glass density of $2.61 \mathrm{~g} / \mathrm{cm}^{3}$.

Table 3 also shows the change in total transmittance of the samples during the exposure test. Positive $\Delta \mathrm{TT}$ values represent an increase in total transmittance. The mean and standard deviation in total transmittance before exposure were 0.7873 and 0.0015 , respectively. Uncertainty is taken to be the rated instrument accuracy of \pm 0.002 .

Results from the RTV, Kapton ${ }^{\text {, }}$, and canted cover glass samples are listed in Table 4. Erosion depth is not given for the RTV sample at $70 \mathrm{deg}$. because the step height was found to be on the order of the surface roughness. No results appear for the OSR samples because they are being analyzed outside GRC, and data were not available in time for inclusion in this paper.

\section{Electromagnetic Interference}

The EMI test was performed at VF6 at NASA GRC and involved measurement of radiated EMI emissions based upon MIL-STD-462 with modifications specific to the SPT-140. Data are presented in comparison to MIL-STD-461 specifications. 


\section{Test Setup}

The EMI test setup was similar to ones used previously at GRC. ${ }^{11,12}$

A portable EMI test pallet was positioned near the middle of the VF6 chamber. It served as a base upon which supports for the thruster and measurement antennas were fixed. as shown in Fig. 6. Atop a $1.4 \mathrm{~m}$ aluminum post attached to the front edge of the EMI pallet. the thruster was mounted with its centerline 0.9 $\mathrm{m}$ below the chamber midpoint, and its beam directed axially toward the pumping end of the chamber. Efield sensing antennas were arrayed in a $1-\mathrm{m}$ radius semicircle behind the thruster exit plane. Each antenna was mounted using fiberglass supports to minimize scattering. A Kapton ${ }^{9}$ tent was erected to enclose the array but exclude the thruster, so that plasma environment effects on the antenna properties were mitigated. A $14-\mathrm{cm}$ diameter loop antenna for the H-held emission measurement was fixed coaxial (1) the thruster centerline $7 \mathrm{~cm}$ behind the back face of the thruster. Residing outside the main Kapton ${ }^{2}$ tent, the H-field loop was enclosed by a separate Kapton ${ }^{\circledR}$ envelope to likewise prevent plasma impingement.

All thruster power supplies were located outside the racuum chamber and fed through via twisted pair, shiekled cables. Antennas were connected via lowInss coaxial cable to EMI receiving equipment located immediately outside the tank feedthrough closest to the antenna array. This included an H.P. $8566 \mathrm{~B}$ (superheterodyne-type. harmonically mixed) spectrum analyzer with $85685 \mathrm{~A}$ preselector and a switch bank of low noise amplifiers (LNAs) used to boost sensitivity at frequencies above $1 \mathrm{GHz}$. Each cohle/filter/LNA/switch path had been calibrated for net gain/loss vs. frequency prior to testing.

\section{Test Procedure}

Software was used to automatically set analyzer parameters and perform frequency sweeps. The spectrum analyzer was operated in peak detection mode for all measurements. This captured an envelope of the peaks, or noise fluctuation maxima, present during a given sweep (in time or frequency domain). Wide frequency ranges were assembled from a composite of many individual sweeps covering smaller frequency spans (Table 5).

To give a background emission reterence, full E-field (MIL-STD-46IC. RE02) and H-field (MIL-STD461D. RE101) sweeps were performed at vacuum with the SPT-140 in an OFF state and unpowered. The sweeps were repeated for two steady state thruster operating points. designated by the discharge powers of 3 and $4.5 \mathrm{~kW}$.

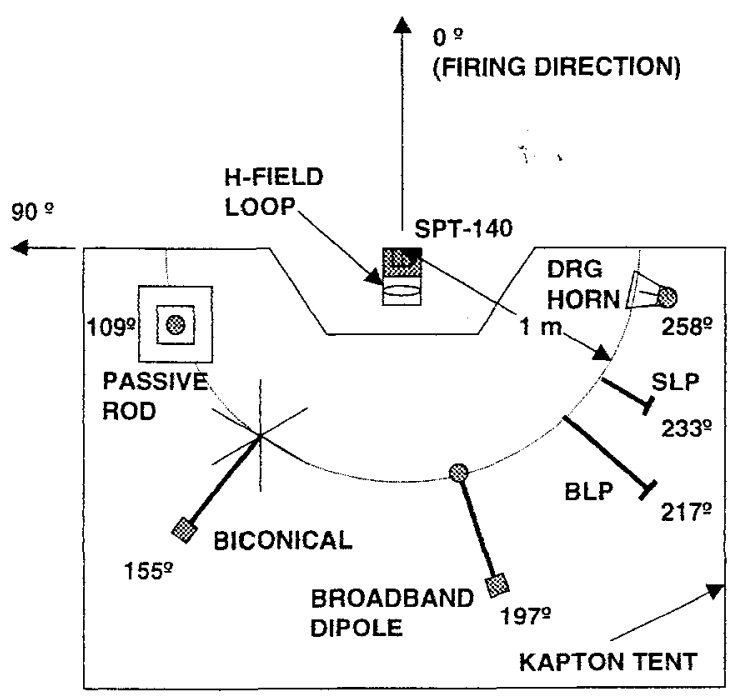

Fig. 7. Top view of EMI pallet.

Table 5. Antennas and broadband measurement bandwidths.

\begin{tabular}{|c|c|c|}
\hline Freq. $(\mathbf{H z})$ & Antenna & $\begin{array}{c}\text { Sweep } \\
\text { Resolution } \\
\text { Bandwidth } \\
\text { (Hz) }\end{array}$ \\
\hline \multicolumn{3}{|c|}{ E-Field } \\
\hline $10 \mathrm{k}-250 \mathrm{k}$ & Passive Rod Band 1 & $3 \mathrm{k}$ \\
\hline $250 \mathrm{k}-500 \mathrm{k}$ & Passive Rod Band 2 & $3 \mathrm{k}$ \\
\hline $500 \mathrm{k}-1 \mathrm{M}$ & Passive Rod Band 3 & $10 \mathrm{k}$ \\
\hline $1 \mathrm{M}-2 \mathrm{M}$ & Passive Rod Band 4 & $10 \mathrm{k}$ \\
\hline $2 \mathrm{M}-4 \mathrm{M}$ & Passive Rod Band 5 & $10 \mathrm{k}$ \\
\hline $4 \mathrm{M}-8 \mathrm{M}$ & Passive Rod Band 6 & $30 \mathrm{~K}$ \\
\hline $8 \mathrm{M}-16 \mathrm{M}$ & Passive Rod Band 7 & $30 \mathrm{k}$ \\
\hline $16 \mathrm{M}-32 \mathrm{M}$ & Passive Rod Band 8 & $30 \mathrm{k}$ \\
\hline $32 \mathrm{M}-200 \mathrm{M}$ & Biconical & $100 \mathrm{k}$ \\
\hline $200 \mathrm{M}-350 \mathrm{M}$ & Broadband Dipole & $300 \mathrm{k}$ \\
\hline $350 \mathrm{M}-1 \mathrm{G}$ & BLP & $300 k$ \\
\hline $1 \mathrm{G}-2 \mathrm{G}$ & \multirow{4}{*}{ DRG Horn } & $3 \mathrm{M}$ \\
\hline $2 \mathrm{G}-4 \mathrm{G}$ & & $3 \mathrm{M}$ \\
\hline $4 \mathrm{G}-8 \mathrm{G}$ & & $3 \mathrm{M}$ \\
\hline $8 \mathrm{G}-18 \mathrm{G}$ & & $3 \mathrm{M}$ \\
\hline \multicolumn{3}{|c|}{ B-Field } \\
\hline $30-1 \mathrm{k}$ & \multirow{3}{*}{ Loop ( $14 \mathrm{~cm} \mathrm{dia.)}$} & 10 \\
\hline $1 \mathrm{k}-10 \mathrm{k}$ & & 100 \\
\hline $10 \mathrm{k}-100 \mathrm{k}$ & & $1 \mathrm{k}$ \\
\hline
\end{tabular}

\section{Results and Discussion}

During thruster operation. the background pressures were $7.2 \times 10^{-6}$ and $9.3 \times 10^{-6}$ Torr (xenon) at 3 and 4.5 $\mathrm{kW}$, respectively.

Fig. 8 and Fig. 9 show the measured E-field emission with the thruster OFF (background) and $O N$, 


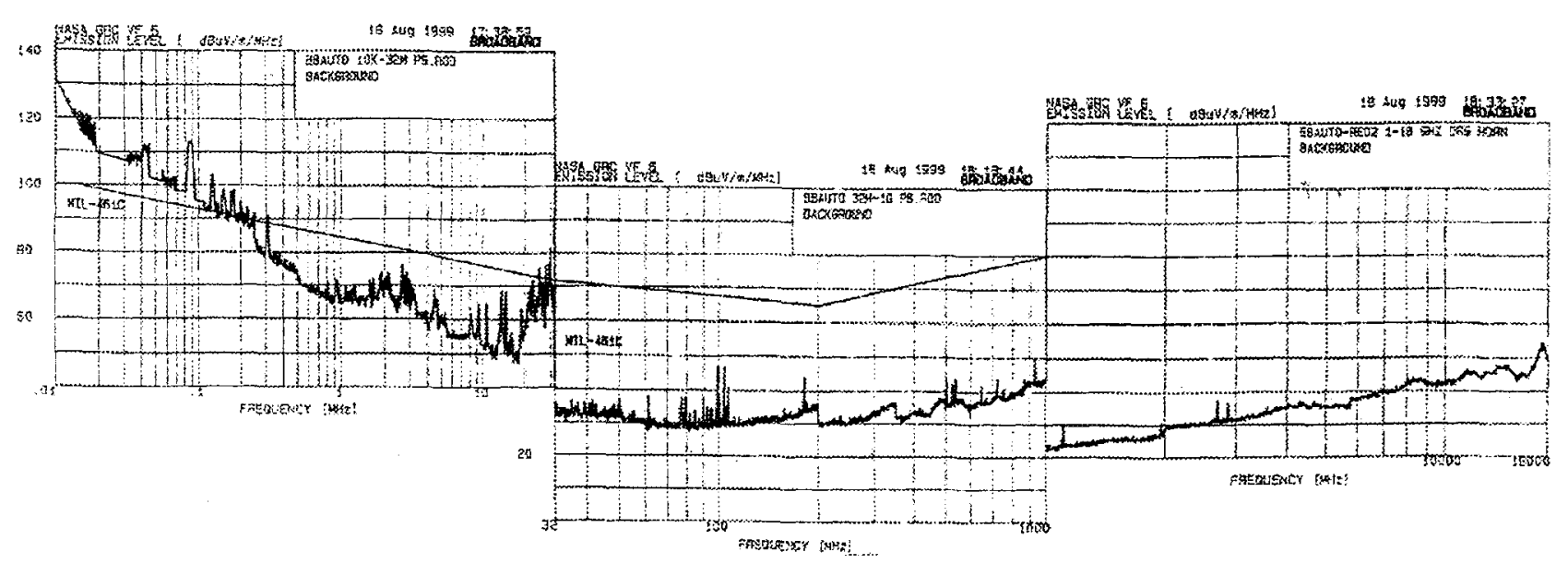

Fig. 8. E-field background/sensitivity threshold. (Note horizontal scale changes at breakpoints.)

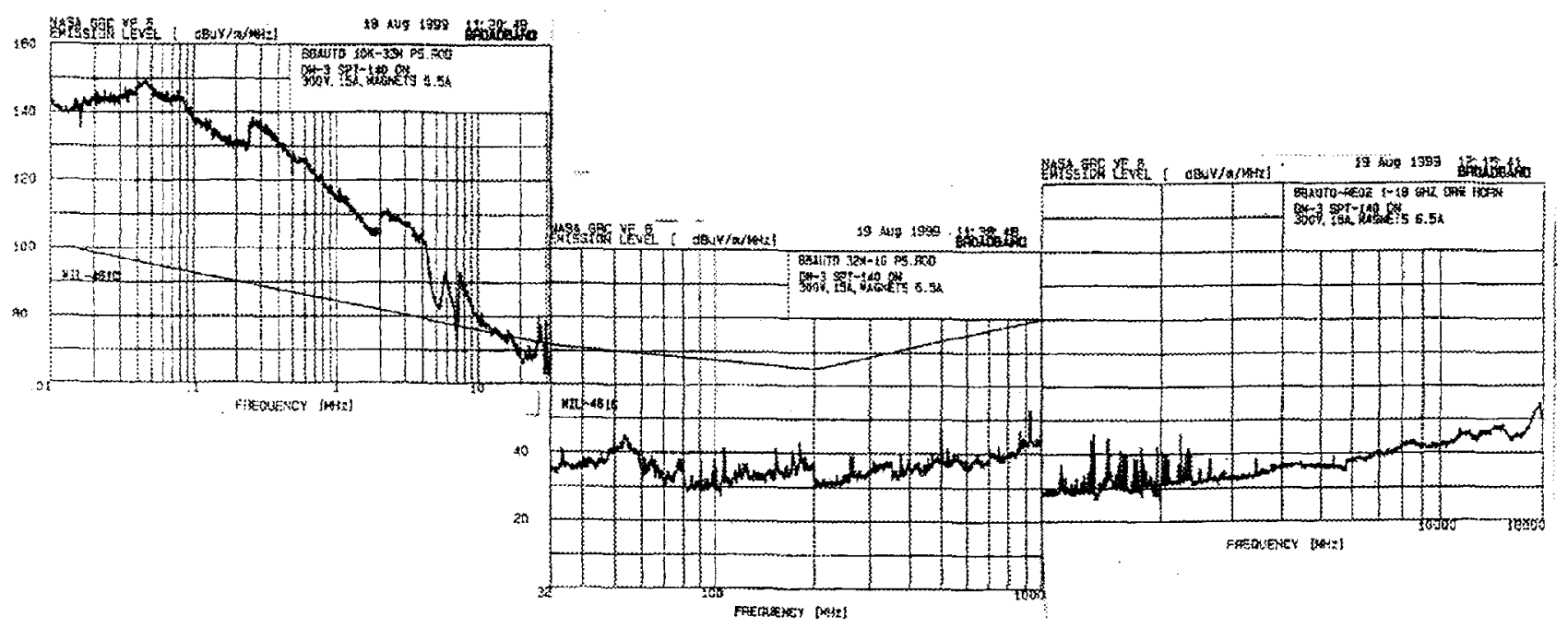

Fig. 9. E-field emissions for thruster firing at $4.5 \mathrm{~kW}$. (Note horizontal scale change at breakpoints.)

respectively. Although the $3 \mathrm{~kW}$ and $4.5 \mathrm{~kW}$ data were similar. the $4.5 \mathrm{~kW}$ emissions were, in general. lightly greater than the $3 \mathrm{~kW}$ emissions. Therefore, only the $4.5 \mathrm{~kW}$ data will be shown in this report.

Thruster E-field emissions exceeded background levels of the sensitivity threshold in the following frequency ranges:

- $10 \mathrm{kHz}$ to $20 \mathrm{MHz}$

- $32 \mathrm{MHz}$ to $80 \mathrm{MHz}$

- $1 \mathrm{GHz}$ to $3 \mathrm{GHz}$

In the 32 to $80 \mathrm{MHz}$ range. several distinct bands of radiated emission are apparent, with a maximum level of $+4 \mathrm{~dB} \mu \mathrm{V} / \mathrm{m} / \mathrm{MHz}$ at $55 \mathrm{MHz}$. However, all detected emissions in this range fall beneath the MILSTD- $46 / \mathrm{C}$ specification. In the range $10 \mathrm{kHz}$ to 20 MHz. however. broadband incoherent-type emissions exceed MIL-STD-46IC specifications by up to $53 \mathrm{~dB}$ ill $45 \mathrm{kHz}$ for the applied worst-case or coherent-type 20) log bandwidth normalization. (The actual emission level corresponding to an incoherent or $10 \mathrm{log}$ bandwidth normalization would exceed the limit by just $29 \mathrm{~dB}$.)

The SPT-140 was found to emit aperiodic broadband emissions at levels above detection threshold from 1 to $3 \mathrm{GHz}$. As no MLL-461C broadband limit exists above $1 \mathrm{GHz}$, comparison against this general standard is not apparent.

Fig. 10 shows the measured $\mathrm{H}$-field emission detected by the $14-\mathrm{cm}$ loop antenna. Like the E-field emission. the $4.5 \mathrm{~kW}$ emissions are the highest, and are presented as the worst case.

Thruster $\mathrm{H}$-field emissions were broadband in nature for the MIL-461D specified measurement bandwidths, and exceeded the background for frequencies greater than $300 \mathrm{~Hz}$. The highest emission levels were reached at $-20 \mathrm{kHz}$, which corresponded to the 


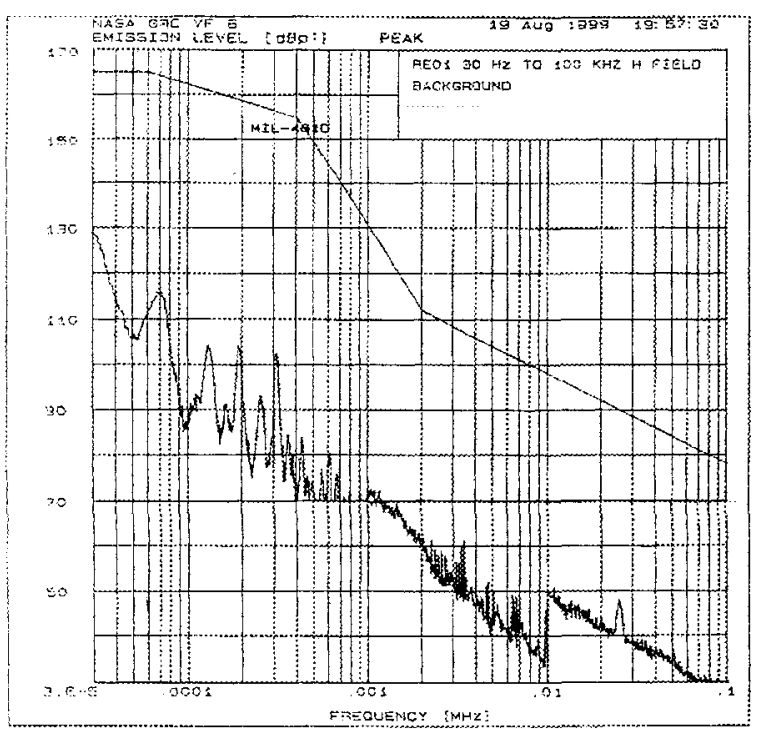

(a)

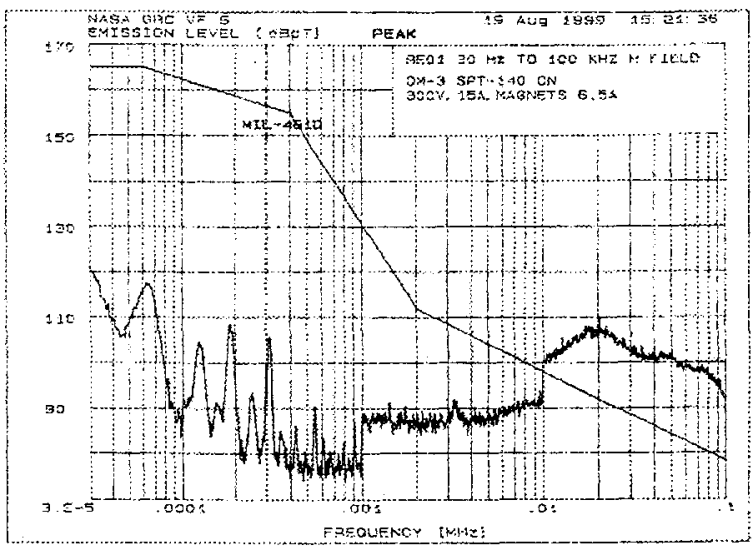

(b)

Fig. 10. H-field emissions from $30 \mathrm{~Hz}$ to $100 \mathrm{kHz}$. a) background b) during thruster firing at $4.5 \mathrm{~kW}$.

frequency of observed discharge current oscillations. Emissions exceeded the MIL-461D RE 101 limit by up to $18 \mathrm{dBpT}$ at frequencies from 10 to $100 \mathrm{kHz}$.

\section{Summary}

In current density measurements showed nearexponential decay with off-axis angle up to approximately 30 degrees. At off-axis angles greater than 30) degrees, results varied with chamber hackground pressure. presumably due to ambient charge exchange plasma. No significant change in the current density was observed for varying rotation angles about the thruster centerine.

Sputtering and contamination tests quantified the erosion depth. mass loss. and solar transmittance of several materials accurately for off-axis angles less than approximately 60 degrees. At off-axis angles greater than 60 degrees, the sputter rate was on the order of the measurement uncertainty. Although uncertainty is high for large off-axis angles, erosion depth and mass loss measurements follow expected trends. and are in agreement with each other.

EMI tests found one band of low-frequency emission (10 $\mathrm{kHz}$ to $20 \mathrm{MHz}$ ) which exceeded the MLL-STDt61C specification by up to $53 \mathrm{~dB}$. However, this is outside the traditionally important RF communications bands.

\section{References}

'Oleson, S. R. and R M. Myers. "Launch Vehicle and Power Level Impacts on Electric GEO Insertion," AIAA-96-2978, 32nd AIAA/ASME/SAE/ASEE Joint Propulsion Conference. Lake Buena Vista. FL, July 1996.

${ }^{2}$ Hargus, W. A. et al., "Preliminary Performance Results of the High Performance Hall System SPT140," AIAA-2000-3250, 36th AIAA/ASME/SAE/ASEE Joint Propulsion Conference. Huntsville, AL. July 2000.

"Kozubsky, K., Kudriavtzev, S., and S. Pridannikov, "Plume Study of Multimode Thruster SPT-140," IEPC-99-073. 26th International Electric Propulsion Conference, Kitakyushu, Japan, October, 1999.

${ }^{4}$ Hofer, R.. Haas, J., and A. Gallimore "Development of a 45-degree Parallel-plate Electrostatic Energy Analyzer for Hall Thruster Plume Studies: Preliminary Data," IEPC-99-113, 26ih International Electric Propulsion Conference, Kitakyushu, Japan, October, 1999.

${ }^{5}$ Myers, R. M. and D. H. Manzella, "Stationary Plasma Thruster Plume Characteristics," IEPC-93096. 23rd International Electric Propulsion Conference. Seattle, WA, September. 1993.

"Manzella. D. H. and J. M. Sankovic, "Hall Thruster Ion Beam Characterization," AIAA-95-2927, 31st AIAA/ASME/SAE/ASEE Joint Propulsion Conference, July, 1995.

${ }^{7}$ Fife, J. M.. "Hybrid-PIC Modeling and Electrostatic Probe Survey of Hall Thrusters," PhD Thesis, 
Massachusetts Institute of Technology, September 1998.

"de Grys. K. H., Tilley, D. L., and R. S. Aadland, "BPT Hall Thruster Plume Characteristics," AIAA-992283. 35th AIAA/ASME/SAE/ASEE Joint Propulsion Conference and Exhibit, Los Angeles, California, June 1999

"Pencil. E.. Randolph. T, and D. Manzella.. "End-oflife Stationary Plasma Thruster Plume Characterization." AIAA-96-2709, 32nd AlAA/ASME/SAE/ASEE Joint Propulsion Conference. July 1996.

${ }^{\mathrm{H}} \mathrm{J}$ aworske, D. A., "Hall Effect Thruster Plume Contamination and Erosion Study." NASA Technical Memorandum. NASA/TM-2000-210204.

"Sarmiento. C. et al.. "RHETT2/EPDM Hall Thruster Propulsion System Electromagnetic Compatability Evaluation." IEPC-97-108. Proceedings of the 25th International Electric Propulsion Conference. August. 1997.

- Manzella. D. et al.. "Performance Evaluation of the SPT-140." IEPC-97-059. 25th International Electric Propulsion Conterence. Cleveland. Ohio. August. 1997. 